\title{
Microwave Assisted Combustion Synthesis and Characterization of Nanocrystalline Nickel-doped Cobalt Ferrites
}

\author{
Marcio Roberto de Freitas ${ }^{a}$, Guilherme Lisboa de Gouveia ${ }^{a}$, Leonardo José Dalla Costa ${ }^{b}$, Adilson \\ Jesus Aparecido de Oliveira ${ }^{b}$, Ruth Herta Goldschmidt Aliaga Kiminami ${ }^{b *}$ \\ ${ }^{a}$ Department of Materials Engineering, Federal University of São Carlos - UFSCAR, Rod. Washington \\ Luiz, km 235, Zip-Code 13565-905, São Carlos, SP, Brazil \\ ${ }^{b}$ Department of Physics, Federal University of São Carlos - UFSCAR, Rod. Washington Luiz, km 235, \\ Zip-Code 13565-905, São Carlos, SP, Brazil
}

Received: January 29, 2016; Revised: May 10, 2016; Accepted: June 25, 2016

\begin{abstract}
Nanoparticles nickel-doped cobalt ferrites $\left[\mathrm{Ni}_{\mathrm{x}} \mathrm{Co}_{1-\mathrm{x}} \mathrm{Fe}_{2} \mathrm{O}_{4}(\mathrm{x}=0.0,0.25,0.50,0.75\right.$ and 1.0 of $\left.\mathrm{Ni}^{2+}\right)$ ] were prepared by the microwave combustion synthesis, using a stoichiometric mixture of metal nitrates and urea as the oxidizer and fuel to drive the reaction. The effect of microwave irradiation on the phase composition was favorable to promote the formation of fluffy foams and nanoparticles sizes. The fast internal heating with microwaves leads to a reduction in synthesis time, to only 2 min. The structural, chemical and magnetic properties of the nickel-doped cobalt ferrites were analyzed by XRD, TEM, SEM and BET. The XRD results confirmed the formation of pure and single-phase spinel structure. The crystallite size of the nanoparticles was in the range of $38-50 \mathrm{~nm}$. SEM images show nanoparticles with spherical shape and homogenous morphology. The TEM analysis shows necked near-spherical particles with an average size of $\sim 30-50 \mathrm{~nm}$, reflecting the highly crystalline nature of these nanoparticles. The magnetic measurements of all the samples were recorded using vibrating sample magnetometer (VSM) at room temperature in $10 \mathrm{kOe}$. Increasing the nickel content directly affects the structural characteristics of the particles, causing a reduction in the coercive field.
\end{abstract}

Keywords: Microwave, combustion synthesis, nickel ferrite, cobalt ferrite, nanoparticles

\section{Introduction}

Magnetic spinel ferrites have been investigated in recent years for their properties and applications in electric and magnetic systems, information storage systems, magnetic cores, microwave absorbers, and medical diagnostics. Attention has focused on the preparation and characterization of superparamagnetic nanoparticles of metal oxides and spinel ferrites $\left(\mathrm{MFe}_{2} \mathrm{O}_{4}\right)(\mathrm{M}=\mathrm{Co}, \mathrm{Mg}, \mathrm{Mn}, \mathrm{Ni} \text {, etc. })^{1-4}$. To minimize the difficulties posed by the mixed oxide method, various methods of chemical synthesis have been used in the laboratory to obtain ferrites, mainly in order to control their microstructure and magnetic properties by controlling characteristics such as purity, chemical homogeneity, shape and mean particle size of powders ${ }^{3-6}$. In the past decade, the solution combustion method was widely used to synthesize single or mixed metal oxides ${ }^{7-12}$. Organic compounds (e.g., glycine, urea, citric acid, alanine and carbohydrazine) have been mixed directly with metal to increase the efficiency of the nitrate combustion synthesis method. Metal nitrates act as oxidants and as sources of cations, and the organic compound acts as fuel ${ }^{12-15}$.

The combustion reaction synthesis of ferrite powders similar to perovskite containing $\mathrm{A}_{2} \mathrm{BO}_{4}$ is a promising alternative process for obtaining Ni-Co ferrites while maintaining

* e-mail: ruth@ufscar.br compositional control ${ }^{12,13}$. Like other methods of synthesis that have been used to prepare ceramic powders, combustion reaction synthesis yields nanometric particles $(<100 \mathrm{~nm})$ with high surface areas. After the reaction has started, the combustion reaction method is self-sustaining and reaches high temperatures, ensuring the rapid formation and crystallization of powders and the release of a large quantity of gas, which in turn tends to minimize particle agglomeration. This process offers advantages over other synthesis methods because it involves a simple reaction, fast preparation of reagents, and allows for control of the characteristics of the final product. Moreover, it requires no intermediate calcination steps and consumes little energy, particularly when using microwave energy as the heat source ${ }^{13}$. Nanostructured ferrites have very promising prospects for application with different properties, although further studies are needed to retain the high density of nanostructures. The magnetic behavior of nanostructures can be influenced by variations in their shape, ranging from the existence of nanodomains to the difference in the distribution of mechanical stresses after sintering ${ }^{14}$. This influence has not been addressed in depth in studies about the influence and magnitude of ferromagnetism in nanostructures. In this context, materials processed by microwave heating have been gaining increasing prominence and importance in many industrial applications because of a number of potential 
advantages it offers over conventional heating methods. Microwave energy offers several benefits, such as shorter processing times and savings in energy, which is why it is being used increasingly in industrial settings ${ }^{13,16}$.

Cobalt ferrite $\left(\mathrm{CoFe}_{2} \mathrm{O}_{4}\right)$ is a well-known hard magnetic material with high coercivity and moderate magnetization, which is useful in high-density digital recording dises and audio/videotape ${ }^{17}$. However, $\mathrm{CoFe}_{2} \mathrm{O}_{4}$ has a high magnetocrystalline anisotropy, which makes it difficult to achieve high initial susceptibility or magnetic conductivity ${ }^{5}$. While nickel ferrite $\left(\mathrm{NiFe}_{2} \mathrm{O}_{4}\right)$ is a typical soft magnetic material with lower magnetocrystalline anisotropy ${ }^{18,19}$, it provides an effective way to reduce the anisotropy of $\mathrm{CoFe}_{2} \mathrm{O}_{4}$ by partly substituting $\mathrm{Co}^{2+}$ for $\mathrm{Ni}^{2+}, \mathrm{Ni}_{\mathrm{x}} \mathrm{Co}_{1-\mathrm{x}} \mathrm{Fe}_{2} \mathrm{O}_{4}$. In view of the above, a new type of nanocomposite, $\mathrm{Ni}_{\mathrm{x}} \mathrm{Co}_{1-\mathrm{x}} \mathrm{Fe}_{2} \mathrm{O}_{4}$, which has controllable magnetic properties, is expected to be used in electromagnetic and nanotechnology applications. The goal of this study is to synthesize nanocrystalline $\mathrm{Ni}_{\mathrm{x}} \mathrm{Co}_{1-}$ ${ }_{x} \mathrm{Fe}_{2} \mathrm{O}_{4}($ where $\mathrm{x}=0.0,0.25,0.50,0.75,1.0)$ by an alternative and relatively new microwave assisted combustion reaction method, using urea as fuel, and to investigate its structural and magnetic properties.

\section{Experimental}

Polycrystalline nickel-doped cobalt ferrites $\left(\mathrm{Ni}_{\mathrm{x}} \mathrm{Co}_{1}\right.$. ${ }_{x} \mathrm{Fe}_{2} \mathrm{O}_{4}$ ), where $\mathrm{x}=0.0,0.25,0.50,0.75$ and 1.0 of $\mathrm{Ni}^{2+}$, were synthesized by the microwave combustion synthesis method. The high purity precursors used in these reactions were: $\mathrm{Fe}\left(\mathrm{NO}_{3}\right)_{3} \cdot 9 \mathrm{H}_{2} \mathrm{O}$ (Merck), $\mathrm{Co}\left(\mathrm{NO}_{3}\right)_{2} \cdot 6 \mathrm{H}_{2} \mathrm{O}$ (Merck), and $\mathrm{Ni}\left(\mathrm{NO}_{3}\right)_{2} \cdot 6 \mathrm{H}_{2} \mathrm{O}$ (Merck) as oxidant and source of cations, while urea $\left[\mathrm{CO}\left(\mathrm{NH}_{2}\right)_{2}\right]$ (Merck) was used as a reducing agent. The synthesis process began by determining the initial mixing ratio of the precursors. Stoichiometric amounts of metal nitrates were dissolved in an aqueous solution of urea, calculated based on the valences of the reactive elements to reach an oxidizer to fuel ratio $=1$, based on the pre-established stoichiometry of the metal ions to form the phases of interest. The precursors were weighed and placed in vitreous silica crucibles, and the desired ratio was obtained by adding $10 \mathrm{ml}$ of distilled water. The aqueous mixtures were stirred with a magnetic stirrer to homogenize the solution. The combustion reactions were performed in a domestic microwave oven operating at a maximum power of $980 \mathrm{~W}$ for $5 \mathrm{~min}$ at a frequency of $2.45 \mathrm{GHz}$. The solution initially boils and then dehydrates, subsequently decomposing and producing large amounts of gas. When the material reaches the point of spontaneous combustion it begins to burn and releases a large amount of heat, vaporizing the solution instantly and turning into a solid, thus forming the desired phase. Experimental measurements of the burning time of the reactions were performed using a CONDOR digital stopwatch. The conventional combustion synthesis takes about 8 min for each reaction ${ }^{13}$.
To investigate the formation of $\mathrm{Ni}_{\mathrm{x}} \mathrm{Co}_{1-\mathrm{x}} \mathrm{Fe}_{2} \mathrm{O}_{4}$ phase, the powder was examined in a Siemens D5000 X-ray diffractometer with $\mathrm{Cu}$ Ka radiation ( $1.5405 \AA$ ), operating for $2 \mathrm{~h}$ at $60 \mathrm{kV}$ and $40 \mathrm{~mA}$ in a range of $10-80^{\circ}$, using a step size of 0.02 and a speed of $5 \% \mathrm{~min}$. XRD patterns obtained from the average crystallite size were calculated from the broadening of X (D311) rays through deconvolution of the diffraction line of the secondary polycrystalline silicon (default), using the Scherrer equation ${ }^{20}$. The nanometric particle size and morphological composition were analyzed using a Philips XL30 FEG scanning electron microscope and a Tecnai G2 F20 transmission electron microscope. A drop of the sample diluted in alcohol was dripped onto the TEM grid and dried to examine the grain size and morphology of the synthesized sample. The specific surface area was determined by the gas adsorption method developed by Brunauer, Emmett and Teller (BET), using a Micromeritics ASAP 2020 surface area and pore size analyzer. The approximate particle size was then calculated based on the specific surface area, using equation $1^{21}$ :

$$
\mathrm{D}_{\mathrm{BET}}=\frac{6}{\mathrm{D}_{\mathrm{t}} \cdot \mathrm{S}_{\mathrm{BET}}}
$$

where: $\mathrm{D}_{\mathrm{BET}}$ is the equivalent spherical diameter $(\mathrm{nm})$, $\mathrm{D}_{\mathrm{t}}$ is the theoretical density $\left(\mathrm{g} / \mathrm{cm}^{3}\right)$, and $\mathrm{S}_{\mathrm{BET}}$ is the surface area $\left(\mathrm{m}^{2} / \mathrm{g}\right)$. To analyze the magnetic properties at room temperature, magnetization as a function of the magnetic field was measured using an EG\&G PAR 4500 vibrating sample magnetometer (VSM) coupled to an electromagnet operating in a maximum range of $10 \mathrm{kOe}$.

\section{Results and Discussion}

The crystal structure of the powder material was analyzed by X-ray diffraction and the resulting XRD pattern of the as-prepared sample is shown in Figure 1. The analysis of the diffraction pattern, based on (220) (310) (311) (222) (400) (333), (511) and (440) reflection planes, confirmed the formation of a cubic structure. In this figure, note the presence of well-defined peaks of the major phase of $\mathrm{Ni}_{1-\mathrm{x}} \mathrm{Co}_{\mathrm{x}} \mathrm{Fe}_{2} \mathrm{O}_{4}$ with good diffraction line broadening, indicating the formation of highly crystalline powders and the complete formation of the Ni-Co ferrite phase. The uniform heating provided by the microwave oven enabled the entire combustion reaction to produce $\mathrm{Ni}_{\mathrm{x}} \mathrm{Co}_{1-\mathrm{x}} \mathrm{Fe}_{2} \mathrm{O}_{4}$ to be completed in only few minutes. The XRD patterns reveal a slight shift in the position of the peaks to smaller interplanar spacing " $\mathrm{d}$ " with increasing concentrations of nickel ${ }^{22}$. The interplanar spacing d ( $\AA$ ) was calculated using Bragg's law. No secondary phase was detected by XRD, thus confirming the purity of the phase of the final product. The microwave combustion reaction time of each composition was approximately $2 \mathrm{~min}$. 


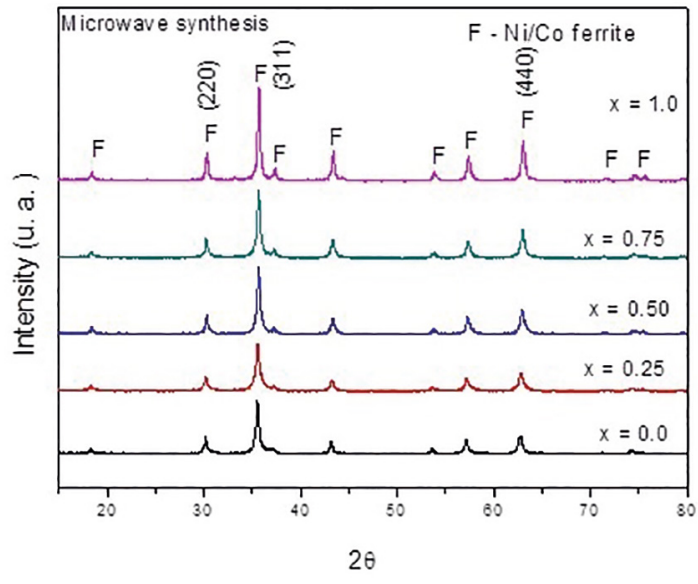

Figure 1: XRD pattern of the $\mathrm{Ni}_{\mathrm{x}} \mathrm{Co}_{1-\mathrm{x}} \mathrm{Fe}_{2} \mathrm{O}_{4}$ nanoparticle system synthesized by the microwave combustion reaction

The lattice parameters "a" were calculated based on the spacings of the respective parameters (hkl) of the samples synthesized by microwave combustion reaction. The "a"

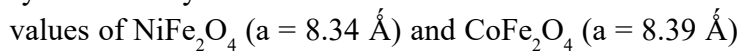
are given in the JCPDS database, and can be explained based

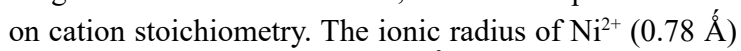
is smaller than that of $\mathrm{Co}^{2+}(0.82 \AA)$, so the substitution of $\mathrm{Co}$ for $\mathrm{Ni}$ in $\mathrm{Ni}_{\mathrm{x}} \mathrm{Co}_{1-\mathrm{x}} \mathrm{Fe}_{2} \mathrm{O}_{4}$ results in a linear dependence of the lattice parameter " $a$ " on the nickel concentration " $\mathrm{x}$ ", according to Vegard's law ${ }^{20}$. The results are depicted in Figure 2. The intensities of the (220) and (440) planes are more sensitive to cations in tetrahedral and octahedral sites, respectively ${ }^{23,24}$. $\mathrm{Ni}^{2+}$ and $\mathrm{Co}^{2+}$ ions prefer octahedral sites, while $\mathrm{Fe}^{3+}$ ions prefer both tetrahedral and octahedral sites. An analysis of Figure 1 clearly indicates that the intensities of the (220) and (440) planes increase in response to increasing concentrations of $\mathrm{Ni}^{2+}$, possibly due to the migration of $\mathrm{Fe}^{3+}$ ions from octahedral to tetrahedral sites, as $\mathrm{Co}^{2+}$ ions are replaced by nickel ions, according to ${ }^{25}$.

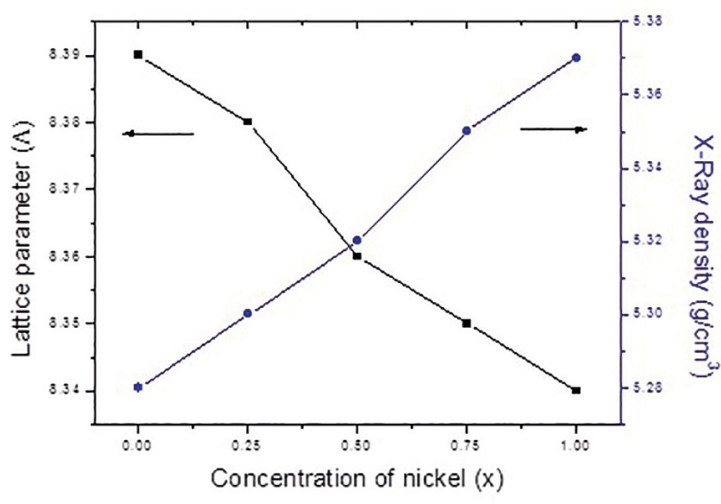

Figure 2: Lattice parameter vs. $\mathrm{X}$-ray density of the $\mathrm{Ni}_{\mathrm{x}} \mathrm{Co}_{1-\mathrm{x}} \mathrm{Fe}_{2} \mathrm{O}_{4}$ system in microwave synthesized samples.
X-ray density was calculated using the equation $\mathrm{d}_{\mathrm{x}}=$ $8 \mathrm{MM} / \mathrm{N} . \mathrm{a}^{3}$, where MM, N and " $\mathrm{a}$ " represent the molar mass, Avogadro's number and the lattice parameter, respectively. This density increases linearly with the increase in nickel concentration (Figure 2), and the lattice parameter " $\mathrm{a}$ " decreases with increasing nickel atoms. The decrease in "a" in response to increasing $\mathrm{Ni}^{+2}$ content also suggests the formation of a compositionally homogeneous solid solution, since "a" was found to be within the range of the lattice constants of $\mathrm{NiFe}_{2} \mathrm{O}_{4}$ (JCPDS card no.44-1185 with $\mathrm{a}=8.381)$ and $\mathrm{CoFe}_{2} \mathrm{O}_{4}$ (JCPDS card no. 1-1121 with $\mathrm{a}=$ 8.39), respectively.

The average crystallite size was calculated from the full-width at half-maximum (FWHM) of the (311) reflection peak (strongest reflection) by applying Scherrer's equation [20]. The structural parameters are given in Table 1. The average crystallite size was found to vary from 49.0 to $37.9 \mathrm{~nm}$ with the increase in $\mathrm{Ni}^{2+}$ concentration from 0.25 to 1.0. The lattice parameter ' $a$ ' was found to increase with $\mathrm{Co}^{2+}$ concentration because the ionic radius of $\mathrm{Co}^{2+}$ is larger than that of $\mathrm{Ni}^{2+}$.

The crystallite size decreased as the nickel content increased. The average crystallite size of the synthesized powders was 38 to $49.0 \mathrm{~nm}$. This can be explained by the fact

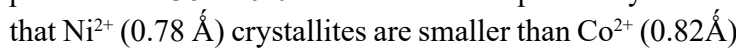
and $\mathrm{Fe}^{3+}(0.67 \AA$ ) crystallites, and the substitution of $\mathrm{Co}$ for $\mathrm{Ni}$ leads to an approximately linear dependence. However, this shift may be due to a change in the $\mathrm{Fe}^{3+}-\mathrm{O}^{2-}$ internuclear distance. $\mathrm{Ni}^{2+}$ ions have a preference for octahedral sites, while $\mathrm{Co}^{2+}$ and $\mathrm{Fe}^{3+}$ ions can occupy both octahedral and tetrahedral sites. Therefore, increasing the $\mathrm{Ni}^{2+}$ concentration forces the $\mathrm{Fe}^{3+}$ ions to occupy tetrahedral sites ${ }^{23,24}$.

Figures 3 (a), (b) and (c) show the results of TEM images of $\mathrm{CoFe}_{2} \mathrm{O}_{4}, \mathrm{Ni}_{0.5} \mathrm{Co}_{0.5} \mathrm{Fe}_{2} \mathrm{O}_{4}$, and $\mathrm{NiFe}_{2} \mathrm{O}_{4}$ samples, respectively. The average particle sizes calculated from the images were $\sim 30 \mathrm{~nm}$ and $\sim 50 \mathrm{~nm}$, and most of the particles were spherical. These results are in good agreement with the peak broadening in the X-ray diffraction data.

Figures 4 (a-e) show micrographs of the morphology of the $\mathrm{Ni}_{\mathrm{x}} \mathrm{Co}_{1-\mathrm{x}} \mathrm{Fe}_{2} \mathrm{O}_{4}$ with different $\mathrm{Ni}$ contents $(\mathrm{x}=0.0,0.25$, $0.5,0.75,1.0)$ nanoparticles systems obtained by microwave combustion synthesis. These micrographs show that all the compositions have a spherical morphology and uniform particle size, consisting only of nanoparticle agglomerates. It is known that the smaller the particle size the greater the surface tension, which generates a driving force that increases agglomeration. Thus, with increasing concentrations of $\mathrm{Ni}^{2+}$, all the compositions studied here showed the formation of soft and friable agglomerates consisting of weak easily disintegrated bonds of irregular morphology and very fine porous particles. The average particle size was smaller than $50 \mathrm{~nm}$, like that reported by Singhal et al. ${ }^{24}$, and decreased slightly with the addition of nickel. 
Table 1: Characteristics of the powders of the $\mathrm{Ni}_{1-\mathrm{x}} \mathrm{Co}_{\mathrm{x}} \mathrm{Fe}_{2} \mathrm{O}_{4}$ system, where $\mathrm{x}=0.0,0.25,0.5,0.75$ and 1.0\%, processed by MWCS

\begin{tabular}{|c|c|c|c|c|}
\hline Method & Composition $\mathrm{Ni}_{\mathrm{x}} \mathrm{Co}_{1-\mathrm{x}} \mathrm{Fe}_{2} \mathrm{O}_{4}$ & $\begin{array}{l}\text { Average particle size (BET) } \\
{[\mathrm{nm}]}\end{array}$ & $\begin{array}{c}\text { Average Crystallite Size } \\
{[\mathrm{nm}]}\end{array}$ & Reaction time (min) \\
\hline \multirow{5}{*}{ MWCS } & $\mathrm{x}=1.0$ & 51.2 & 38.0 & 2.3 \\
\hline & $x=0.75$ & 58.0 & 41.4 & 2.3 \\
\hline & $x=0.50$ & 60.9 & 42.7 & 2.1 \\
\hline & $x=0.25$ & 71.0 & 48.4 & 2.3 \\
\hline & $\mathrm{x}=0.0$ & 85.5 & 49.0 & 2.3 \\
\hline
\end{tabular}
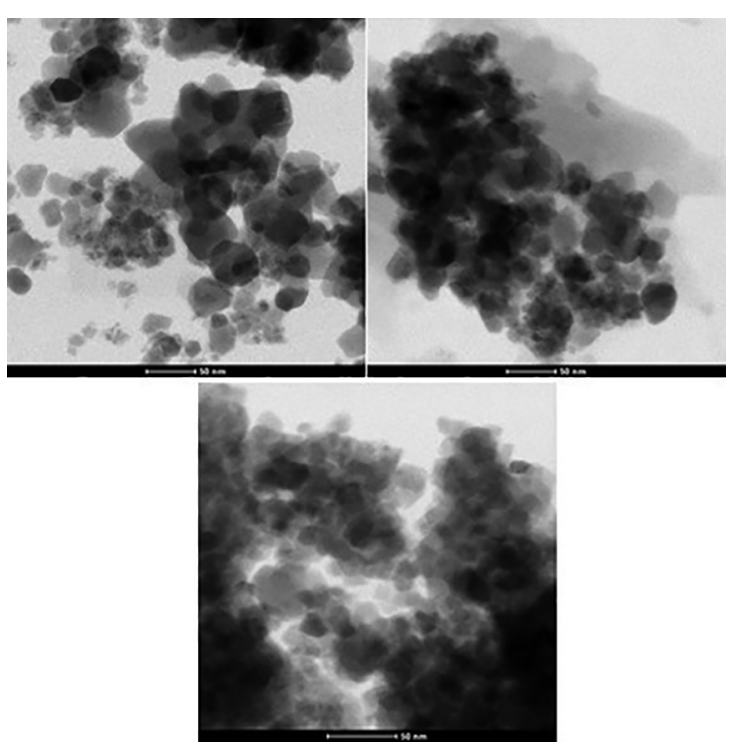

Figure 3: TEM micrographs of $\mathrm{Ni}_{\mathrm{x}} \mathrm{Co}_{1-\mathrm{x}} \mathrm{Fe}_{2} \mathrm{O}_{4}$, where: a) $\mathrm{x}=\mathrm{CoFe}_{2} \mathrm{O}_{4}$, b) $\mathrm{x}=\mathrm{Ni}_{0.5} \mathrm{Co}_{0.5} \mathrm{Fe}_{2} \mathrm{O}_{4}$, and c) $\mathrm{x}=\mathrm{NiFe}_{2} \mathrm{O}_{4}$.

The room temperature magnetization of $\mathrm{Ni}_{\mathrm{x}} \mathrm{Co}_{1-\mathrm{x}} \mathrm{Fe}_{2} \mathrm{O}_{4}$ nanoparticles with different $\mathrm{Ni}$ contents $(\mathrm{x}=0.0,0.25,0.5$, $0.75,1.0)$ was measured with a vibrating sample magnetometer (VSM) and the resulting $\mathrm{M}-\mathrm{H}$ curves are shown in Figure 5. Note that the curves of the $\mathrm{MxH}$ samples show hysteresis corresponding to each composition. As can be seen in Fig. 4 , the samples exhibit a particle size in the range of 30 to $50 \mathrm{~nm}$, with all the samples presenting a different coercive field and saturation magnetization (Ms) of the cobalt ferrite, and in both case decreased as the concentration of nickel in the composition increased.

Table 2 describes the magnetic parameters (coercive field, saturation magnetization, remanent magnetization) obtained from the $\mathrm{M} \times \mathrm{H}$ curves.

A comparison of the systems revealed a reduction in saturation magnetization. This indicates that the substitution of cobalt for nickel was adequate, because a loss in magnetization was observed, confirming the ferromagnetic characteristics of these samples. These results support the data reported by $\mathrm{Kasapoglu}^{26}$. Furthermore, it is known that extrinsic features such as particle size influence the area of the magnetic field and can contribute to reduce magnetization, because the larger the particle and/or grain size the fewer the number of barriers, leading to higher magnetization.
In this work, we found that the coercivity (Hc) varied with nickel doping, because the increase of the nickel content in cobalt ferrite, favored the reduction of the coercive field ( $\mathrm{Hc}$ ) and reduced particle size, as shown in Table 1. These results corroborate those of the literature ${ }^{25,26}$. Thus, it is evident the influence of nickel instead of cobalt ions to cobalt ferrite in the network in both the synthesis and as the morphological characteristics of the magnetic powders synthesized by microwave assisted combustion reaction. Figures 5 and Table 2 show hysteresis loops for $\mathrm{Ni}_{x} \mathrm{Co}_{1-\mathrm{x}} \mathrm{Fe}_{2} \mathrm{O}_{4}$ nanoparticles at room temperature for the samples synthesized by MWCS. Samples more easily saturate with increasing $\mathrm{Ni}$ content, which is expected as $\mathrm{Ni}$ ferrite is a soft and Co ferrite a hard magnetic material. Figure 5 show, at room temperature, $\mathrm{CoFe}_{2} \mathrm{O}_{4}$ shows coercivity (Hc) of $1031.81 \mathrm{Oe}$ while $\mathrm{Ni}_{0.5} \mathrm{Co}_{0.5} \mathrm{Fe}_{2} \mathrm{O}_{4}$ and $\mathrm{NiFe}_{2} \mathrm{O}_{4}$ exhibit coercivities of $941.1 \mathrm{Oe}$ and 193.3 $\mathrm{Oe}$, respectively. Although the coercivity of $\mathrm{CoFe}_{2} \mathrm{O}_{4}$ is higher, its room temperature coercivity is lower than that of the bulk ferrite. The results show a linear decrease in coercive field with increasing concentration of $\mathrm{Ni}$ for the samples. The coercivity of a magnetic material is roughly a measure of its magnetocrystalline anisotropy. Co ferrite usually forms an inverse spinel structure with very high anisotropy energy constants ( $\mathrm{K} 1$ and $\mathrm{K} 2$ ). It is also temperature sensitive at lower temperatures. As the $\mathrm{Ni}$ content of $\mathrm{Ni}_{\mathrm{x}} \mathrm{Co}_{1-\mathrm{x}} \mathrm{Fe}_{2} \mathrm{O}_{4}$ increases, the decrease in coercivity indicates that anisotropy decreases, which in turn reduces the domain wall energy. The antiferromagnetic interaction decreases and the ferromagnetic super exchange interaction increases as $\mathrm{Co}^{2+}$ ions are substituted for $\mathrm{Ni}^{2+}$ ions, which leads to decreased coercivity and magnetization.

\section{Conclusions}

We successfully employed microwave assisted combustion reaction to synthesize nanocrystalline $\mathrm{Ni}_{\mathrm{x}} \mathrm{Co}_{1-\mathrm{x}} \mathrm{Fe}_{2} \mathrm{O}_{4}$ from nitrate precursors, using urea as fuel. The results indicated that the material had a spinel structure and was of high purity. The lattice parameter decreased with increasing nickel content. The crystallite size was estimated at $\sim 38$ 

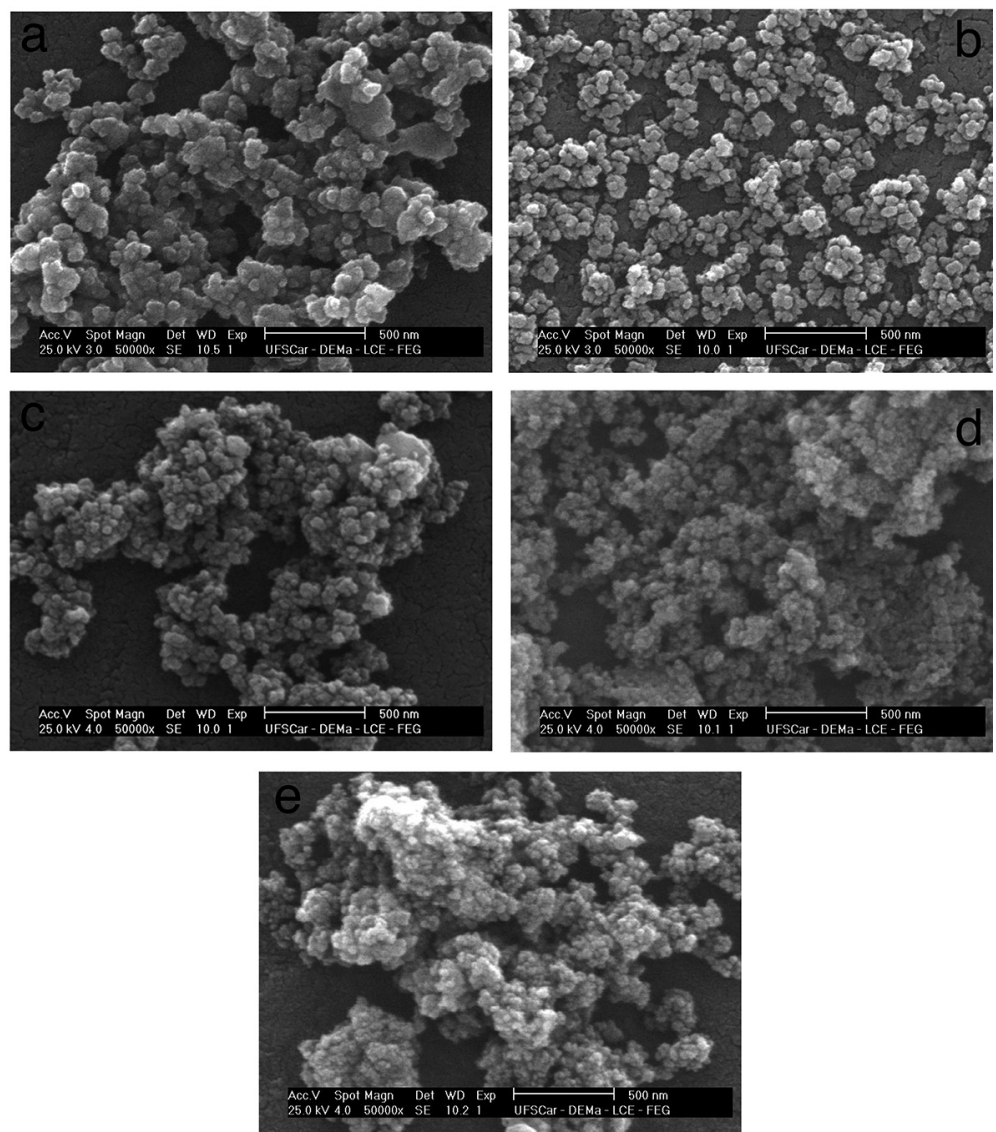

Figure 4: SEM micrographs of the morphology of powders synthesized by MWCS (50,000 X magnification): a) $x=0 ; b) x=0: 25 ; c)$ $=0: 50 ;$ and $\mathrm{d}) \mathrm{x}=1.0$

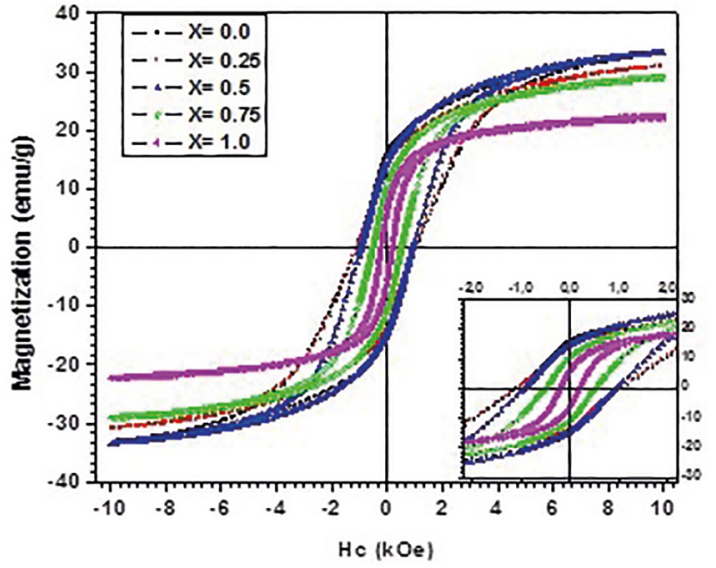

Figure 5: Magnetization as a function of applied magnetic field of nickel-doped cobalt ferrites powders measured at room temperature to $50 \mathrm{~nm}$ by X-ray line profile fitting. Near-spherical and necked particles with an average size of 30 to $50 \mathrm{~nm}$ were observed by TEM, reflecting the high crystallinity of these nanoparticles.

The results of this study demonstrate that the fast internal heating with microwaves leads to a reduction in synthesis time, to just two minutes, preventing excessive particle growth and the formation of large aggregate. Increasing the nickel content directly affects the structural characteristics of the particles, causing a reduction in the coercive field. The magnetic characteristics of polycrystalline nickel-doped cobalt ferrites $\left(\mathrm{Ni}_{\mathrm{x}} \mathrm{Co}_{1-\mathrm{x}} \mathrm{Fe}_{2} \mathrm{O}_{4}\right)$, where $\mathrm{x}=0.0,0.25,0.50,0.75$, and 1.0 of $\mathrm{Ni}^{2+}$, differ according to the amount of $\mathrm{Ni}$ used, enabling these ferrites to be used as soft and hard magnetic materials with adequate magnetization cycles.

Table 2. Magnetic parameters of powders obtained by microwave combustion synthesis.

\begin{tabular}{lccccc}
\hline & $\mathrm{CoFe}_{2} \mathrm{O}_{4}$ & $\mathrm{Ni}_{0.25} \mathrm{Co}_{0.75} \mathrm{Fe}_{2} \mathrm{O}_{4}$ & $\mathrm{Ni}_{0.50} \mathrm{Co}_{0.50} \mathrm{Fe}_{2} \mathrm{O}_{4}$ & $\mathrm{Ni}_{0.75} \mathrm{Co}_{0.25} \mathrm{Fe}_{2} \mathrm{O}_{4}$ & $\mathrm{NiFe}_{2} \mathrm{O}_{4}$ \\
\hline $\mathrm{Ms}(\mathrm{emu} / \mathrm{g})$ & 33.5 & 30.9 & 33.3 & 29.0 & 22.4 \\
$\mathrm{Mr}(\mathrm{emu} / \mathrm{g})$ & 15.6 & 13.9 & 14.3 & 10.0 & 5.1 \\
$\mathrm{Hc}(\mathrm{Oe})$ & 1032 & 1037 & 941 & 512 & 193 \\
\hline
\end{tabular}




\section{Acknowledgements}

The authors acknowledge the financial support of the Brazilian research funding agencies FAPESP (São Paulo Research Foundation) (Process no. 08/04025-0) and CAPES (Federal Agency for the Support and Improvement of Higher Education).

\section{References}

1. Qu Y, Yang H, Yang N, Fan Y, Zhu H, Zou G. The effect of reaction temperature on the particle size, structure and magnetic properties of coprecipitated $\mathrm{CoFe}_{2} \mathrm{O}_{4}$ nanoparticles. Materials Letters. 2006;60(29-30):3548-3552.

2. Hochepied JF, Bonville P, Pileni MP. Nonstoichiometric Zinc Ferrite Nanocrystals: Synthesis and Unusual Magnetic Properties. Journal of Physical Chemistry B. 2000;104(5):905-912.

3. Liu C, Zou B, Rondinone AJ, Zhang ZJ. Reverse micelle synthesis and characterization of superparamagnetic $\mathrm{MnFe}_{2} \mathrm{O}_{4}$ spinel ferrite nanocrystallites. Journal of Physical Chemistry B. 2000;104(6):1141-1145.

4. Fannin PC, Marin CN, Malaescu I, Stefu N, Vlazan P, Novaconi S, et al. Microwave absorbent properties of nanosized cobalt ferrite powders prepared by coprecipitation and subjected to different thermal treatments. Materials \& Design. 2011;32(3):1600-1604.

5. Shi Y, Ding J, Yin $\mathrm{H}$. $\mathrm{CoFe}_{2} \mathrm{O}_{4}$ nanoparticles prepared by the mechanochemical method. Journal of Alloys and Compounds. 2000;308(1-2):290-295.

6. Bhise RB, Rathod SM, Supekar AK. Magnetic, Electric and Structural Properties of Ni Substituted Co-Zn Ferrite Nanoparticles Synthesized by Sol-Gel Method. Journal of Applied Physics. 2012;2(4):7-12.

7. Mimani T, Patil KC. Solution combustion synthesis of nanoscale oxides and their composites. Materials Physics and Mechanics. 2001;4(2):134-139.

8. YPFu, CH Lin. Microwave-induced combustion synthesis of $\mathrm{Ni}-\mathrm{Zn}$ ferrite powder and its characterization. Journal of Magnetism and Magnetic Materials. 2002;251(1):74-79.

9. Costa ACFM, Tortella E, Morelli MR, Kiminami RHGA. Synthesis, microstructure and magnetic properties of $\mathrm{Ni}-\mathrm{Zn}$ ferrites. Journal of Magnetism and Magnetic Materials. 2003;256(1-3):174-182.

10. Fu YP, Pan KY, Lin CH. Microwave-induced combustion synthesis of $\mathrm{Ni}_{0.25} \mathrm{Cu}_{0.25} \mathrm{Zn}_{0.5}$ ferrite powders and their characterizations. Materials Letters. 2002;57(2):291-296.

11. Merzhanov AG. The chemistry of self-propagating hightemperature synthesis. Journal of Materials Chemistry. 2004;14(12):1779-1786.

12. Baykal A, Kasapoğlu N, Köseoğlu Y, Basaran AC, Kavas H, Toprak MS. Microwave-induced combustion synthesis and characterization of $\mathrm{Ni}_{\mathrm{x}} \mathrm{Co}_{1-\mathrm{x}} \mathrm{Fe}_{2} \mathrm{O}_{4}$ nanocrystals $(\mathrm{x}=0.0,0.4,0.6,0.8,1.0)$. Central European Journal of Chemistry. 2008;6(1):125-130.
13. Costa ACFM, Morelli MR, Kiminami RHGA. Combustion synthesis processing of nanoceramics. In: Tseng TI, Nalwa HS, eds. Handbook of nanoceramics and their based nanodevices (Synthesis and Processing). Vol 1. Valencia: American Scientific Publishers; 2009. p. 375-391.

14. Eerenstein W, Wiora M, Prieto JL, Scott JF, Mathur ND. Giant sharp and persistent converse magnetoelectric effects in multiferroic epitaxial heterostructures. Nature Materials. 2007;6(5):348-351.

15. Jain RS, Adiga KC. A new approach to thermochemical calculations of condensed fuel-oxidizer mixtures A new approach to thermochemical calculations of condensed fuel-oxidizer mixtures A new approach to thermochemical calculations of condensed fuel-oxidizer mixtures. Combustion and Flame. 1981;40:71-79.

16. Gunnewiek RFK, Kiminami RHGA. Effect of heating rate on microwave sintering of nanocrystalline zinc oxide. Ceramics International. 2014;40(7, Part B):10667-10675.

17. Blaskov V, Petkov V, Rusanov V, Martinez LM, Martinez B, Muñoz JS, et al. Magnetic properties of nanophase $\mathrm{CoFe}_{2} \mathrm{O}_{4}$ particles. Journal of Magnetism and Magnetic Materials. 1996;162(23):331-337.

18. Maaz K, Khalid W, Mumtaz A, Hasanin SK, Liu J, Duan JL. Magnetic characterization of $\mathrm{Co}_{1-x} \mathrm{Ni} \mathrm{Fe}_{2} \mathrm{O}_{4}(0 \leq x \leq 1)$ nanoparticles prepared by co-precipitation route. Physica E: Low-dimensional Systems and Nanostructures. 2009;41(4):593-599.

19. Sirvetz MH, Saunders JH. Resonance widths in polycrystalline nickel-cobalt ferrites. Physical Review. 1956;102(2):366-367.

20. Cullity BD. Elements of $X$-ray diffraction. Reading: AddisonWesley; 1987.

21. Reed JS. Principles of Ceramics Processing. 2nd ed. New York: John Wiley; 1995. 688p.

22. Hankare PP, Sanadi KR, Garadkar KM, Patil DR, Mulla IS. Synthesis and characterization of nickel substituted cobalt ferrite nanoparticles by sol-gel auto-combustion method. Journal of Alloys and Compounds. 2013;553:383-388.

23. Zālīte I, Heidemane G, Kodols M, Grabis J, Maiorov M. The synthesis, characterization and sintering of nickel cobalt ferrite nanopowders. Materials Science. 2012;18(1):1392-1320.

24. Singhal S, Singh J, Barthwal SK, Chandra K. Preparation and characterization of nanosize nickel-substituted cobalt ferrites $\left(\mathrm{Co}_{1-x} \mathrm{Ni}_{x} \mathrm{Fe}_{2} \mathrm{O}_{4}\right)$. Journal of Solid State Chemistry. 2005;178(10):3183-3189.

25. Sathishkumar G, Venkataraju C, Sivakumar K. Synthesis, Structural and Dielectric Studies of Nickel Substituted Cobalt-Zinc Ferrite. Materials Sciences and Applications. 2010;1(1):19-24.

26. Kasapoglu N, Birsoz B, Baykal A, Koseoglu Y, Toprak MS. Microwave-induced combustion synthesis and characterization of $\mathrm{Ni}_{\mathrm{x}} \mathrm{Co}_{-\mathrm{x}} \mathrm{Fe}_{2} \mathrm{O}_{4}$ nanocrystals $(\mathrm{x}=0.0,0.4,0.6,0.8,1.0)$. Central European Journal of Chemistry. 2008;6(1):125-130. 